\title{
Visual claudicatio: diagnosis with 64-slice computed tomography
}

\author{
Filippo Cademartiri · Erica Maffei · \\ Alessandro Palumbo · Nico R. Mollet • \\ Aad van der Lugt $\cdot$ Girolamo Crisi
}

Received: 27 July 2006/ Accepted: 21 August 2006/Published online: 22 March 2007

(C) Springer Science+Business Media B.V. 2007

\begin{abstract}
We present a case of a 78-year-old male referred presented to our institution with amaurosis fugax after walking 20 steps ("visual claudicatio"). Duplex ultrasound was not able to visualize the carotid arteries. Multislice computed tomography (Sensation 64 Cardiac, Siemens, Germany) of the cerebro-vascular circulation was performed from its origin at the level of the aortic arch to the circle of Willis. The investigation demonstrated a complete occlusion of both common carotid arteries at their origin and a severe origo stenosis of both vertebral arteries. An important collateral circulation of the vertebral arteries through the minor vessels of the neck was also displayed. Both comunicans posterior arteries were small but patent. The intra-cranial arteries
\end{abstract}

Electronic Supplementary Material The online version of this article (doi: 10.1007/s10554-006-9155-y) contains supplementary material, which is available to authorized users.

F. Cademartiri $(\bowtie) \cdot$ E. Maffei $\cdot$ A. Palumbo

G. Crisi

Department of Radiology, Azienda Ospedaliero-

Universitaria di Parma, Via Gramsci, 14, 43100

Parma, Italy

e-mail: filippocademartiri@hotmail.com

N. R. Mollet · A. van der Lugt · F. Cademartiri ·

A. Palumbo

Department of Radiology, Erasmus Medical Center,

Rotterdam, The Netherlands were patent. Multislice CT of the cerebro-vascular circulation is an optimal tool for a comprehensive evaluation when duplex ultrasound fails.

Keywords 64-slice CT · CT angiography · Carotid artery stenosis $\cdot$ Diagnosis

\section{Introduction}

Stroke (brain attack) represents one of the most serious causes of mortality and morbidity in the United States and throughout the world. Each year, 150,000 patients die as a direct result of a cerebro-vascular accident (CVA), while 600,000 patients experience the morbidity of aphasia, blindness, or paralysis. Among patients with stroke, extra-cranial carotid disease represents the cause of approximately one half of cases. The goals of carotid imaging can be described as early detection, clinical staging, surgical road mapping, and postoperative therapeutic surveillance. The gold standard for the study of carotid and vertebral arteries is conventional digital subtraction angiography (DSA). Non invasive techniques, such as duplex-ultrasound, computed tomography (CT), and magnetic resonance imaging allow to study segments of the cerebro-vascular circulation. The introduction on multislice CT, especially with the latest 64-row equipments, significantly improved scan range, scan speed and image quality $[1,2]$. 


\section{Case description}

A 78-year-old male was referred to our institution because of amaurosis fugax after walking 20 steps ("visual claudicatio"). A previous carotid ultrasound was not able to visualize the carotid arteries in their usual anatomical location. Therefore, it was decided to proceed with a contrast-enhanced multislice CT (Sensation 64 Cardiac, Siemens, Germany) of the cerebro-vascular circulation from its origin at the level of the aortic arch to the circle of Willis.

The scan parameters for 64-slice CT Coronary Angiography were: individual detector width $0.6 \mathrm{~mm}$, gantry rotation time $330 \mathrm{~ms}$, effective temporal resolution $165 \mathrm{~ms}$ (with single segment reconstruction algorithm), $\mathrm{kV} \mathrm{120,} \mathrm{eff.} \mathrm{mAs} \mathrm{180,}$ pitch factor 1 , scan direction cranio-caudal. The acquisition time takes from 12-15 s [3-6].

A bolus of $60-80 \mathrm{ml}$ contrast material with high iodine concentration (350-400 mg of Iodine per $\mathrm{ml}$ ) is injected through the brachial vein with a flow rate of $4-5 \mathrm{ml} / \mathrm{s}$. A test bolus or a bolustracking technique may be used to synchronize the arrival of contrast in the coronary arteries with the initiation of the scan. Bolus tracking technique is more reliable and allows to reduce the volume of contrast material [3-6].

The resulting images (Fig. 1) demonstrated a complete occlusion of both common carotid arteries at their origin and a severe origo stenosis of both vertebral arteries. An important collateral circulation of the vertebral arteries through the minor vessels of the neck was also displayed. Both comunicans posterior arteries were small but patent. The intra-cranial arteries were patent. The plain CT scan of the brain showed only a lacunar lesion in the left internal capsule. The patient is on follow-up and no immediate treatment option has been planned.

\section{Discussion}

Acute ischemic neurologic symptoms are related to small-vessel disease of the intracranial perforating arteries, thromboembolism from atherosclerotic disease in the supraaortic arteries, and cardiac embolism [7]. The most common source of thromboembolism is atherosclerotic disease of the carotid bifurcation.

However, atherosclerotic lesions in the aorta, the origin of the supraaortic arteries, the common carotid artery (CCA), the internal carotid artery (ICA) distal to the bifurcation, and the vertebrobasilar circulation can cause transient ischemic attack or ischemic stroke due to thromboembolism [8, 9]. In the evaluation of patients with cerebro-vascular disease, complete vascular imaging from the aorta to the circle of Willis must be performed before therapeutic decision making can be undertaken.

There are three well known criteria for the quantification of carotid artery stenosis and they are all based on longitudinal assessment of the carotid bifurcation [10]. These three criteria are: the North American Symptomatic Carotid Endarterectomy Trial (NASCET), the European Carotid Surgery Trialists (ECST), and the Common Carotid (CC).

The advantage of CT in these settings is that virtually any plane and projection can be generated and any method can be applied also in unfavourable conditions.

CT angiography can be considered as a noninvasive gold standard for the evaluation of cerebro-vascular diseases.

CT angiography is not limited by plane constraints and therefore could always perform the adequate cross-sectional plane [11]. Current criteria for stenosis assessment are based on the historical gold standard of conventional angiography $[12,13]$. For the assessment of the degree of stenosis in the coronary arteries QCA (i.e. quantitative coronary angiography) represents the clinical gold standard. However, more accurate (and more invasive) methods are available, such as intravascular ultrasound (IVUS) [14]. IVUS allows cross-sectional imaging of coronary artery lumen and, when available, is the actual gold standard for coronary wall and lumen assessment. Intra-arterial technique is rarely used for the assessment of carotid arteries and almost never for clinical purposes. This is also due the easier accessibility of carotid arteries by other non-invasive techniques.

In analogy with IVUS, CT angiograpy has the potential to provide reliable cross-sectional 

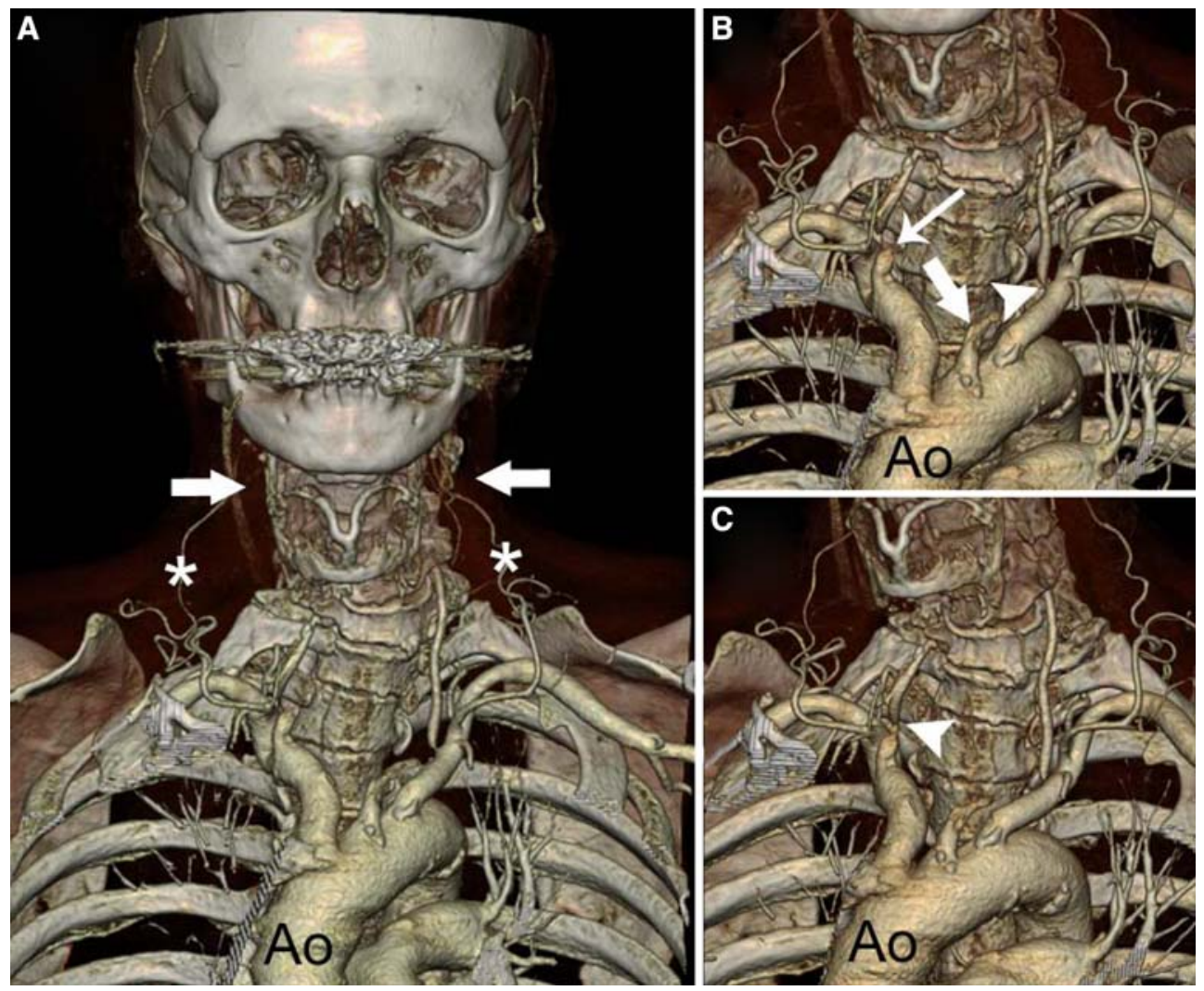

Fig. 1 Three-dimensional volume rendering of the multislice CT dataset. The three-dimensional volume rendering of the entire dataset (A) shows the origin of the supra-aortic arteries at the level of the aortic arch (Ao) in standard configuration, the absence of carotid arteries in the region of the neck on both sides (arrows), and the presence of evident collateral circulation (asterisks) through the thyro-

imaging of carotid plaques for the evaluation of vessel lumen and wall.

\section{Conclusion}

Multislice CT is a reliable and non-invasive tool for the assessment of vascular diseases that affects the branches of the aortic arch, especially when the first line tools (i.e. duplex ultrasound) are not able to provide reliable information.

\section{References}

1. Ohnesorge BM, Hofmann LK, Flohr TG, Schoepf UJ (2005) CT for imaging coronary artery disease: defining the paradigm for its application. Int $\mathbf{J}$ Cardiovasc Imaging 21:85-104 cervical trunks. A magnified view performed with slightly different angles at the level of the origin of the supra-aortic arteries (B and $\mathbf{C})$ shows the occlusion of the right $(\mathbf{B}-$ thin arrow) and left common carotid artery (B-thick arrow), and the severe stenosis of the left (B-arrowhead) and right vertebral artery $(\mathbf{C}$-arrowhead)

2. Nikolaou K, Flohr T, Knez A, Rist C, Wintersperger B, Johnson T, Reiser MF, Becker CR (2004) Advances in cardiac CT imaging: 64-slice scanner. Int J Cardiovasc Imaging 20:535-540

3. Cademartiri F, Malagutti P, Belgrano M, Runza G, Pugliese F, Mollet NR, Meijboom WB, Krestin GP, De Feyter PJ (2005) Non-invasive coronary angiography with 64-slice computed tomography. Minerva Cardioangiol 53:465-472

4. Cademartiri F, Runza G, Belgrano M, Luccichenti G, Mollet NR, Malagutti P, Silvestrini M, Midiri M, Cova M, Pozzi Mucelli R, Krestin GP (2005) Introduction to coronary imaging with 64-slice computed tomography. Radiol Med (Torino) 110:16-41

5. de Monye C, Cademartiri F, de Weert TT, Siepman DA, Dippel DW, van der Lugt A (2005) Sixteendetector row CT angiography of carotid arteries: comparison of different volumes of contrast material with and without a bolus chaser. Radiology 237:555-562

6. de Monye C, de Weert TT, Zaalberg W, Cademartiri F, Siepman DA, Dippel DW, van der Lugt A (2006) 
Optimization of CT angiography of the carotid artery with a 16-MDCT scanner: craniocaudal scan direction reduces contrast material-related perivenous artifacts. AJR Am J Roentgenol 186:1737-1745

7. Warlow C, Sudlow C, Dennis M, Wardlaw J, Sandercock P (2003) Stroke. Lancet 362:1211-1224

8. Ersoy H, Watts R, Sanelli P, Zimmerman RD, Kent KC, Bush HL, Prince MR (2003) Atherosclerotic disease distribution in carotid and vertebrobasilar arteries: clinical experience in 100 patients undergoing fluoro-triggered 3D Gd-MRA. J Magn Reson Imaging 17:545-558

9. Rouleau PA, Huston J III, Gilbertson J, Brown RD Jr, Meyer FB, Bower TC (1999) Carotid artery tandem lesions: frequency of angiographic detection and consequences for endarterectomy. AJNR Am J Neuroradiol 20:621-625

10. Bartlett ES, Walters TD, Symons SP, Fox AJ (2006) Quantification of carotid stenosis on CT angiography. AJNR Am J Neuroradiol 27:13-19

11. Bartlett ES, Symons SP, Fox AJ (2006) Correlation of carotid stenosis diameter and cross-sectional areas with CT angiography. AJNR Am J Neuroradiol 27:638-642

12. Eliasziw M, Rankin RN, Fox AJ, Haynes RB, Barnett HJ 1995 Accuracy and prognostic consequences of ultrasonography in identifying severe carotid artery stenosis. North American Symptomatic Carotid Endarterectomy Trial (NASCET) Group. Stroke 26:17471752

13. Randomised trial of endarterectomy for recently symptomatic carotid stenosis: final results of the MRC European Carotid Surgery Trial (ECST) (1998) Lancet 351:1379-1387

14. Van Mieghem CA, McFadden EP, de Feyter PJ, Bruining N, Schaar JA, Mollet NR, Cademartiri F, Goedhart D, de Winter S, Granillo GR, Valgimigli M, Mastik F, van der Steen AF, van der Giessen WJ, Sianos G, Backx B, Morel MA, van Es GA, Zalewski A, Serruys PW (2006) Noninvasive detection of subclinical coronary atherosclerosis coupled with assessment of changes in plaque characteristics using novel invasive imaging modalities: the Integrated Biomarker and Imaging Study (IBIS). J Am Coll Cardiol 47:1134-1142 